\section{Some comments on Thomas' (1977) reciprocal inhibitory model for monocular rivalry}

\section{PETER WALKER \\ Preston Polytechnic, Preston PRI 7DP, England}

Thomas (1977) has recently discussed the relationship between the spatial frequency of superimposed grating patterns and their rate of monocular rivalry. On the basis of this relationship and a number of other observations, he concludes that reciprocal (lateral) inhibition underlies monocular rivalry. On several counts, however, such a hypothesis is not only unjustified but is contradicted by the evidence that is available.

The first point that may be made is that it is by no means clear how reciprocal inhibition might begin to explain even the most fundamental features of monocular rivalry, viz, the dominance of one pattern and the alternation in dominance. Why, for example, when one pattern is dominant, should the other pattern ever return to dominance? Indeed, if one pattern is "stronger" than the other, why should it ever be rendered nondominant?

More particularly, Thomas draws heavily on his own findings, and those of Kitterle, Kaye, and Nixon (1974), which show an inverted U-shaped function relating the rate of pattern alternation with the spatial frequency of one or both gratings-the optimum frequency being approximately $5 \mathrm{c} / \mathrm{deg}$. Thomas argues that this result supports the reciprocal inhibition model because $5 \mathrm{c} / \mathrm{deg}$ patterns are particularly effective stimuli for the visual system, and hence would create powerful reciprocal inhibition between their respective neural channels. More powerful inhibition would, according to Thomas, bring about a faster rate of alternation. Similarly, Kitterle et al. (1974) argue that obliquely oriented gratings alternate less frequently than vertical and horizontal gratings because they are less effective stimuli for the visual system, inducing less lateral inhibition. While Kitterle et al. refer to other researches which justify the assumption regarding the relative effectiveness of oblique vs. horizontal/vertical gratings, Thomas does not draw on other data to confirm the relative effectiveness of $5 \mathrm{c} / \mathrm{deg}$. To this extent, his argument is rather circular. This aside, however, it is still unclear how these effects are to be accommodated by reciprocal inhibition. For example, if both stimuli are increased in "strength," not only might the strength of inhibition between them be made more powerful, but, by definition, the strength of activation of the channels themselves would also increase. Could not this latter increase more than compensate the former increase, so that less rivalry would be predicted? Clearly, any model based on reciprocal inhibition must specify the nature of a presumably complex relationship between the strength of direct activation of the individual channels and the strength of their reciprocal inhibition.

Thomas also mentions in support of his hypothesis that the rate of alternation decreases as the spatial frequency of the grating patterns is made increasingly different. His argument is that providing such a difference in spatial frequency should result in fewer alternations because of a weakened inhibitory interaction. Unfortunately, Thomas' own study and that of Kitterle et al., from which support is derived, confound the difference in spatial frequency with the absolute values for these frequencies.

If one next. considers other evidence regarding monocular rivalry, one discovers further grounds for rejecting Thomas' hypothesis.

Thomas draws our attention to the fact that while orientation-sensitive channels respond to orientations that deviate by as much as $10^{\circ}-15^{\circ}$ from their preferred orientation, monocular rivalry is not observed until the orientations of two superimposed gratings differ by a least $15^{\circ}-20^{\circ}$. The suggestion is that only when such an orientation difference occurs does lateral inhibition between the corresponding channels arise. The evidence indicates, however, that lateral inhibition may be observed between channels whose preferred orientations are within $15^{\circ}-20^{\circ}$ of each other (Blakemore \& Tobin, 1972; Carpenter \& Blakemore, 1973). More important, however, if one considers the effect of increasing the orientational separation of superimposed gratings beyond $20^{\circ}$, then, while the strength of the lateral inhibition between their respective channels decreases (Blakemore \& Tobin, 1972; Carpenter \& Blakemore, 1973), the rate of monocular rivalry actually increases (Campbell, Gilinsky, Howell, Riggs, \& Atkinson, 1973). There is, then, a negative correlation between the occurrence or rate of monocular rivalry and the magnitude of the underlying lateral inhibition (see Walker, 1976). Consistent with this is the fact, acknowledged by Thomas, that the rate of monocular rivalry is greater for differently colored gratings (e.g., one in red and the other in green) (Rauschecker, Campbell, \& Atkinson, 1973). This also contradicts Thomas' hypothesis, since lateral inhibition between orientationsensitive channels is selective to wavelength (Lovegrove, 1977).

In conclusion, there seems to be little support for Thomas' reciprocal inhibition approach to visual rivalry. Rather, the evidence would appear to support the counter proposal that the readiness with which two patterns engage in rivalry is positively correlated with the extent to which their respective channels are 
independent and do not interact via lateral inhibition (Walker, 1976, in press).

\section{REFERENCES}

Blakemore, C., \& Tobin, E. A. Lateral inhibition between orientation detectors in the cat's visual cortex. Experimental Brain Research, 1972, 15, 439-440.

Campbell, F. W., Gilinsky, A. S., Howell, E. R., Riggs, L. A., \& Atkinson, J. The dependence of monocular rivalry on orientation. Perception, 1973, 2, 123-125.

Carpenter, R. H. S., \& Blakemore, C. Interactions between orientations in human vision. Experimental Brain Research, $1973,18,287-303$.

Kitterle, F. L., Kaye, R. S., \& Nixon, H. Pattern alternation: Effects of spatial frequency and orientation. Perception \& Psychophysics, 1974, 16, 543-547.
LOVEgrove, W. Inhibition between channels selective to contour orientation and wavelength in the human visual system. Perception \& Psychophysics, 1977, 22, 49-53.

Rauschecker, J. P. J., Campbell, F. W., \& Atkinson, J. Colour opponent neurons in the human visual system. Nature, 1973, 245, 42-43.

Thomas, J. A reciprocal inhibitory model for monocular pattern alternation. Perception \& Psychophysics, 1977, 22, 310-312.

W ALKER, P. The perceptual fragmentation of unstabilized images. Quarterly Journal of Experimental Psychology, 1976, 28, 35-45. WALKER, P. Orientation-selective inhibition and binocular rivalry. Perception, 1978, 7, 207-214.

(Received for publication April 13, 1978; accepted April 13, 1978.) 